\title{
Kalvaryumda Multifokal Osteosarkom: Nadir Bir Vaka Sunumu ve Literatür Derlemesi
}

\author{
Multifocal Osteosarcoma in the Calvarium: A Rare Case Report and Literature Review
}

\section{Neslihan KURTUL ${ }^{1}$, Nursel YURTTUTAN ${ }^{2}$, A. Yasir BAHAR ${ }^{3}$, Gökmen AKTAŞ ${ }^{4}$}

${ }^{1}$ Dr. Öğr. Üyesi. Kahramanmaraş Sütçü İmam Üniversitesi Tip Fakültesi Radyasyon Onkolojisi AD, KAHRAMANMARAŞ
${ }^{2}$ Doç. Dr. Kahramanmaraş Sütçü İmam Üniversitesi Tip Fakültesi Radyoloji AD, KAHRAMANMARAŞ
${ }^{3}$ Dr. Öğr. Üyesi. Kahramanmaraş Sütçü İmam Üniversitesi Tip Fakültesi Patoloji AD, KAHRAMANMARAŞ
${ }^{4}$ Dr. Öğr. Üyesi. Kahramanmaraş Sütçü İmam Üniversitesi Tip Fakültesi Tibbi Onkoloji BD, KAHRAMANMARAŞ

\section{$\ddot{O} z$}

Kalvaryum kaynaklı osteosarkomlar oldukça nadir görülmektedir. Diğer yandan multifokal vakalar ise yok denecek kadar azdır. Bu nedenle standart tedavi yaklaşımları bilinmemektedir. Biz bu çalışmada 22 yaşında kalvaryumda multifokal osteosarkom nedeniyle cerrahi sonrası radyoterapi ve kemoterapi alan hastayı ve tedavi sonuçlarını inceledik

\section{Abstract}

Osteosarcomas originating from Kalvarium are very rare. On the other hand, multifocal osteosarcoma of the skull is very rare. In this study, we investigated the patient who received radiotherapy and chemotherapy after surgery formultifocal osteosarcoma at the age of 22 years.

\section{GİRIS}

Osteosarkomlar pediatrik grupta en sık görülen malign kemik tümörleridir. Adolesan ve 65 yaş üzeri olmak üzere iki dönemde pik yapar. Genellikle uzun kemiklerin metafizinde görülür. Yaklaşık \%6 kadarı kraniofasial kemiklerden kaynaklanır (1). Tüm osteosarkomların \%2'si ise kalvaryum kaynaklıdır (2). Multifokal osteosarkomlar gençlerde daha sıktır (3). Birden fazla lezyonun eş zamanlı olarak veya baskın bir lezyondan birkaç hafta sonra ortaya çıan diğer lezyonlar şeklinde görülebilir. En sık osteoblastik osteosarkom olarak tanı alır ve çok agresifseyirlidir. Literatürde multifokal kalvaryum yerleşimli birkaç vaka bildirilmiştir. Oldukça nadir görüldüğünden standart tedavi yaklaşımı bilinmemektedir. Bu çalışmada kalvaryumda birden fazla odakta gözlenen osteosarkom olgusunun tedavi ve klinik seyrini inceledik.

\section{OLGU SUNUMU}

Yaklaşık6ayönce sağparietal bölgedehızlabüyüyen şişlik ve baş ağrısı nedeniyle başka bir merkezde opere edilen 22 yaşında erkek hasta kalvaryumda yeniden ve çok sayıda lezyon gelişmesi üzerine hastanemize başvurdu. Özgeçmişinde 6 yıldır uyuşturucu madde kullanımı vardı herhangi bir ek hastalığı yoktu. Çekilen kranial MR'da frontal $9 \times 4 \mathrm{~cm}$, temporal $7 \times 5 \mathrm{~cm}$ ve parietal $4 \times 4 \mathrm{~cm}$ ve $3 \times 1,5 \mathrm{~cm}$ multible aynı karakterde lezyonlar görüldü (Resim 1). Hastaya frontal ve parietal lezyona total, frontale subtotal kitle eksizyonu yapıldı. Beyin dokusunda invazyonu değerlendirmek üzere örnekleme yapıldı. Patolojik incelemede yaygın osteid matriks ve anaplastik sarkomatöz tümör hücreleri mevcuttu. Tümörde 10 büyük büyütme alanında 7 mitoz izlendi. Perinöral invazyon mevcuttu. Nekroz ve lenfovasküler invazyon izlenmedi.
Patolojik olarak beyin dokusuna invazyon yoktu (Resim 2). Bu bulgularla hastaya osteoblastik tip, yüksek gradlı osteosarkom tanısı koyuldu. Evreleme amaçlı çekilen PET-CT'de uzak metastaz bulgusuna rastlanmadı. Lokal hastalık ve şiddetli ağrı nedeniyle öncelikle radyoterapi (RT) planlandı. RT planı yapılırken çekilen MR'da sol parietal ve frontal lobda geçirilmiş operasyona sekonder değişiklikler izlendi. Sol temporalsubdural mesafeden mediale uzanım gösteren $75 \times 17 \mathrm{~mm}$ boyutlarında T1A hipo T2A hiperintens paternde IVKM enjeksiyonu sonrası yoğun kontrast tutulumu gösteren ekstraaksiyel rezidü kitle lezyonu izlendi. İlk cerrahisinden yaklaşık 6 ay sonra rezidü progrese tümör ve postoperatif alanı yeterli sınırla içerecek şekilde hedef volüm oluşturuldu. Hedef volüme komșu normal beyin dokusu tolerans dozları göz önünde bulundurularak 30 fraksiyonda 6000 cGy doz tanımlandı (Resim 3). Daha sonra tümör yanıtına göre extraaksiyel lezyonlar için 66-70 Gy’e kadar adaptif RT düşünüldü. Ancak 6000 cGy sonrası çekilen MR'da temporal lezyonda progresyon gözlenmesi üzerine cisplatin, adriamisin kemoterapisi başlandı ve RT tamamlandı. RT bittikten yaklaşık 6 hafta sonra KT sırasında hastada akciğer metastazı gelişti. Bu süreçte kalvaryumdaki kitle boyutu stabil seyretti ancak 3 kür KT yanıtını değerlendirmek için çekilen MR progresyon şeklinde raporlandı. Yeniden cerrahi yapıldı. Rezeksiyon materyali komplet tümör nekrozu, grade 4 tümör yanıtı olarak geldi. KT'ye devam edildi. KT sonrası akciğer metastazlarında tam yanıt gözlendi. Kranial MR'da temporal alanda rezidü ve progrese kitle, diğer alanlarda nüks olmaksızın hasta tanıdan 21 ay sonra KT 'ye devam etmektedir.

$\begin{array}{llll}\text { İletişim: } & \text { Dr. Neslihan Kurtul, KSÜ Tip Fakültesi, Kahramanmaraş } & \text { Tel } & : 05067872841 \\ & & \text { E-Posta }: \text { drneslihankurtul@gmail.com } \\ & & \text { Geliş Tarihi : } 15.03 .2019 \\ \text { DOI: } & \mathbf{1 0 . 1 7 5 1 7 / k s u t f d . 5 4 0 3 0 5} & \text { Kabul Tarihi : } 22.03 .2019\end{array}$




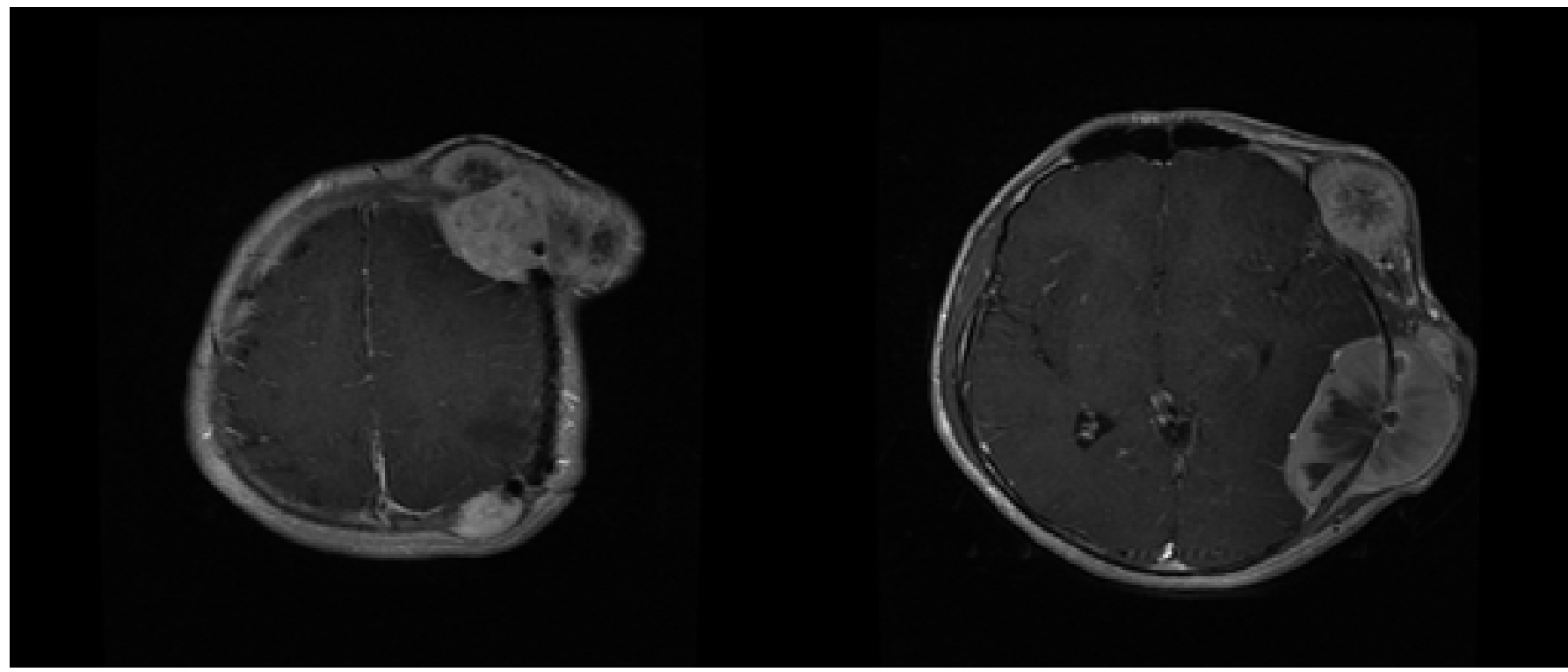

Resim 2. Mikroskopik değerlendirmede eozinofilik, 'lace-like' neoplastik osteid üreten, bazıları 'bizarre' görünümde, high grade atipik spindle hücrelerden oluşan malign tümör mevcuttur (solda, 10x hematoksilen-eozin). 'On high magnification' osteid içerisinde ve etrafında çok sayıda atipik hücre ve atipik mitotik figür (ok ile işaretli) görülmektedir (sağda, 40x hematoksilen-eozin).

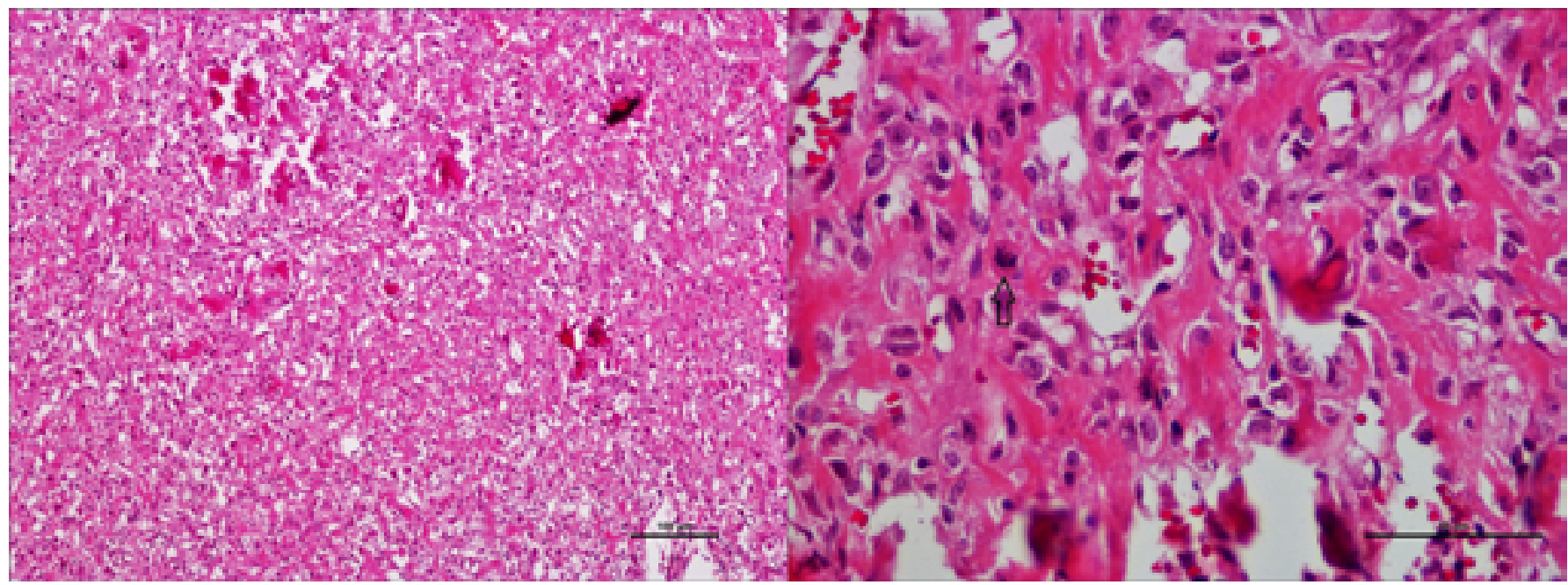

Resim 3. Simülasyon tomografisi ile füzyon yapılan T1 kontrastlıMR'da planlanan hedef volümdeki (kırmızı çizgi) \%95'lik izodoz bölgesi.

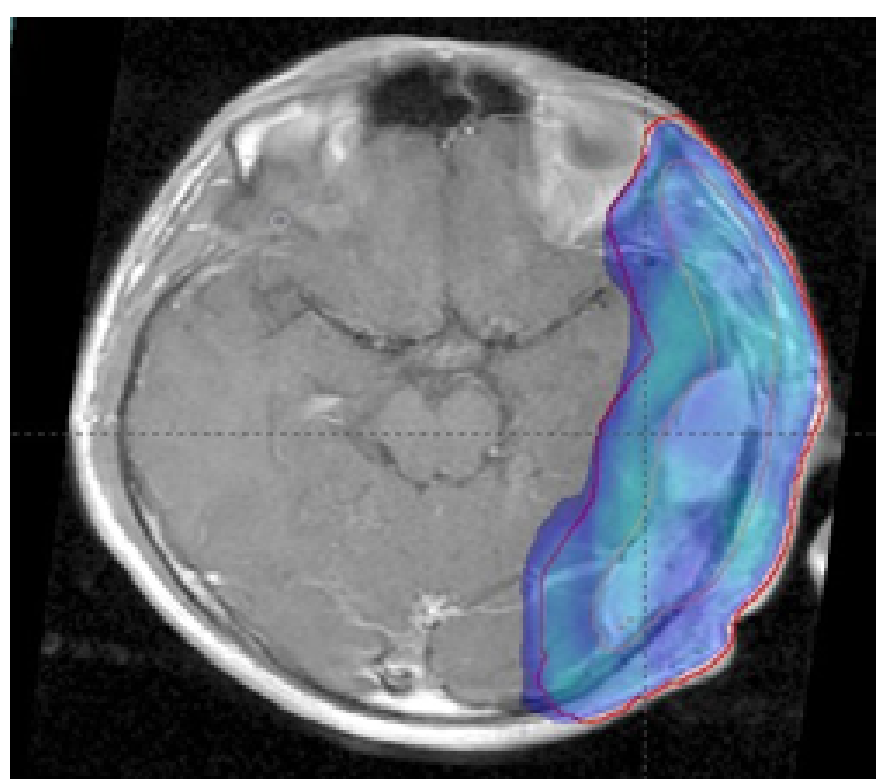

\section{TARTISMA}

Kemiğin primer maling tümörleri oldukça az görülür ve tüm kanserlerin \% 2'sini oluşturmaktadır. Bununla birlikte osteosarkomlar çocukluk ve adolesan dönemde en sık görülen 5. malignite ve en sık görülen malign kemik tümörüdür (4). Erkeklerde daha sık görülür. Yaşam boyu insidansı çocukluk-adölesan ve 65 yaş üstü olmak üzere iki dönemde artmaktadır. Kalvaryum kaynaklı osteosarkomlar ise en sık 3. dekatta görülmektedir (5). Çocukluk çağında genellikle sporadik gelişirken, yaşlilarda paget ya da diğer bening kemik oluşumlarının sarkomatöz dejenerasyonları ile ilişkilidir. Başka bir kanser nedeniyle kemoterapi ve radyoterapiye maruziyet, retinoblastom ve Li-fraumeni sendromu gibi faktörler etyolojisinde yer almaktadır. Bizim hastamız da literatürle uyumlu olarak 22 yaşında ve erkekti. Özgeçmişinde tümör öyküsü ya da sendromyoktu.

Osteosarkom en sik distal femur (\% 42), tibia (\% 19), humerus (\% 10) gibi uzun kemiklerin metafizinden kaynaklanan tek lezyon şeklindedir (6). Daha az sıklıkla pelvis ve kraniofasial kemiklerde görülür. 
Multifokalosteojenik sarkom ilk kez 1936'da Silverman tarafından tanımlanmıștır (7). Osteosarkom vakalarının $\%$ 1'i ile \% 3'ü multifokal olarak görülmektedir (8). Bizim araștırmamıza göre tanı anında kalvaryumda ve multifokal 3 vaka bildirilmiștir $(6,9,10)$. Zafad ve ark.larının çalışmasında 12 yaşında erkek çocuk frontoparietal bölgede intra ve ektrakranial uzanımı olan lezyonla başvurdu. Üç hafta sonra kafatasında iki ek lezyon, solskapular lezyon ve pelviklezyon saptandi. Kranial tümör üzerinde yapilan cerrahi biyopside osteoblastikosteosarkom tanısı aldı. Yüksek doz metotreksat ve doksorubisin kemoterapisi ald 1 ve 9 ay sonra hayatını kaybetti (9). Diğer çalışmada 40 yaşında erkek hastada bel ağrısı nedeniyle çekilen MR'da multipl ekstradural lezyonlar görüldü. Kemik sintigrafisinde kalvaryumu da içeren birçok kemikte tutulum izlendi. Sol femurdaki dominant lezyondan yapilan biopsi osteoblastik osteosarkoma ile uyumlu geldi. Hastaya iki kür metotreksat, adriamisin ve cisplatin kemoterapisi verildi. Daha sonra intraserebral hemorajiyle șiddetli baş ağrisına neden olan sağ oksipital kemikteki lezyon eksize edildi ve patolojisi yine osteoblastik osteosarkoma olarak raporlandı hasta tanı anından 14 ay sonra hayatını kaybetti (10). Cho ve ark ise parietal kemikte birbirinden $1,7 \mathrm{~cm}$ uzaklıkta iki osteoblastom odağ 1 tesbit edilen 58 yaşındaki bayan hastayı sundular. Cerrahiden 2 ay sonra hastaya kemoterapi başland, ancak sol atriumda metastatik lezyon görüldü. Lezyon eksize edildi ve metastatik osteoblastom tanısı aldı. Yazarlar cerrahi sonrası 4 ayda kemik sintigrafisinde tutulum olmayan hastanın, hastalık rekurrensi ya da progresyon olmadan kemoterapiye devam ettiğini bildirdiler (6). Bizim vakamızda da Cho ve ark vakasındaki gibi tutulumlar sadece kranial kemiklerde idi. Başlangıçta tek büyük lezyon iken cerrahi sonrası Zafad ve ark olgusundaki gibi multipl lezyonlarla nüks etti. Ancak, PET-CT'de vücudun başka bir yerinde metastaz ya da senkron primer odak görülmedi.

Ekstremitelerde görülen osteosarkom tedavisinde neoadjuvan KT ile birlikte sağlam cerrahi sinırla organ koruyucu cerrahi mümkündür. Ancak komplet rezeksiyonun neredeyse hiç mümkün olmadığı pelvis, vertebra ve kalvaryumda yüksek rekürrens oranları görülmektedir (\% 70, \% 68, \%5 0, sirasiyla) (11-13). RT bu hastalarda lokal kontrolü arttırabilir. Osteosarkomda RT, yakın ya da pozitif cerrahi sınır, opere edilemeyecek tümörler ve ağrilı lezyon palyasyonu amaciyla uygulanmaktadır. Bizde hastamızın tedavisine nüks kitle, ciddi başağrısı ve subtotal eksizyon nedeniyle öncelikle RT ile başladık. Ekstremite osteosarkomlarında RT, 2 Gy'lik fraksiyonlarda, mikroskobik hastalıkta $60 \mathrm{~Gy}$, makroskopik rezidüel hastalık için $66 \mathrm{~Gy}$, inoperabl tümörler için ise 70 Gy kullanılır. Makroskopik rezidü olmasına rağmen normal beyin dokusu tolerans dozları nedeniyle biz hastamızda 60 Gy RT uyguladık (14). Progresyon gelişmesi üzerine KT ile devam ettik. Ancak hasta KT ile yine progrese oldu ve yeniden cerrahiye yönlendirildi. Gupta ve ark parietalde tek lezyonu olan hastada cerrahi sonrası KT ile progresyon bildirdiler ve recerrahi sonrası RT uyguladilar (14). Adjuvan tedavide RT ve KT birlikte yan etkilerde artış nedeniyle kullanılmamaktadır. Bununla birlikte sıralamasının nasıl olması gerektiği bilinmemekte, onkolojik sonuçlar vaka bazında bildirilmektedir. Kalvaryumda tek lezyonlu osteosarkomların değerlendirildiği derlemede tedavi alan 65 hastanın 32'sine RT uygulanmıştır (15). Ancak sadece kalvaryumda multipl odaklı olan vakada (6) muhtemelen temiz cerrahi sınır nedeniyle RT uygulanmamıştır. Çok odaklı lezyonlar ışınlanacak volümü arttırmış olmakla birlikte tedaviden sonra 1. yılda hastamızda RT'ye bağlı herhangi bir komplikasyon görülmedi.

Sonuç olarak çok odaklı osteosarkomlar oldukça nadir görülüp, agresif seyretmektedir. Rezeksiyon derecesi progresyonda en önemli faktör gibi gözükmektedir. Tedavi

\section{KAYNAKLAR}

1. Huvos AG, Woodard HQ, Cahan WG, Higinbotham NL, Stewart FW, Butler A et al. Postradiation osteogenic sarcoma of bone and soft tissues. A clinicopathologic study of 66 patients. Cancer 1985;55(6):1244-55.

2. Nora F, Unni K, Pritchard D, Dahlin D. Osteosarcoma of extragnathic craniofacial bones. In, Mayo Clinic Proceedings; 1983:268-72.

3. Hopper KD, Moser Jr R, Haseman DB, Sweet DE, Madewell JE, Kransdorf MJ. Osteosarcomatosis. Radiology 1990;175(1):233-9.

4. Gurney J, Swensen A, Bulterys M. SEER Pediatric Monograph. National Cancer Institute 2005,

5. Oda D, Bavisotto LM, Schmidt RA, McNutt M, Bruckner JD, Conrad III EU et al. Head and neck osteosarcoma at the University of Washington. Head \& Neck: Journal for the Sciences and Specialties of the Head and Neck 1997;19(6):513-23.

6. Cho H, Park B-j, Park Y-K. Multifocal osteosarcoma of the skull: multiple primary or metastatic? A case report. Korean journal of pathology 2014;48(2):146.

7. Silverman G. Multiple osteogenic sarcoma. Arch Pathol 1936;21:88-95.

8. Currall VA, Dixon JH. Synchronous multifocal osteosarcoma: case report and literature review. Sarcoma 2006;2006

9. Zafad S, Madani A, Harif M, Quessar A, Trachli A, Benchekroun S. Multifocal osteosarcoma. A case report. Archives de pediatrie: organe officiel de la Societe francaise de pediatrie 2000;7(10):1077-80.

10. Sato H, Hayashi N, Yamamoto H, Nagai S, Ohmori $\mathrm{K}$, Kanamori $\mathrm{M}$ et al. Synchronous multifocal osteosarcoma involving the skull presenting with intracranial hemorrhage. Neurologia medicochirurgica 2010;50(5):407-9.

11. Ozaki T, Flege S, Kevric M, Lindner N, Maas $\mathrm{R}$, Delling Gn et al. Osteosarcoma of the pelvis: experience of the Cooperative Osteosarcoma Study Group. Journal of clinical oncology 2003;21(2):33441.

12. Ozaki T, Flege S, Liljenqvist U, Hillmann A, Delling 
G, Salzer-Kuntschik M et al. Osteosarcoma of the spine: experience of the Cooperative Osteosarcoma Study Group. Cancer 2002;94(4):1069-77.

13. Kassir RR, Rassekh CH, Kinsella JB, Segas J, Carrau RL, Hokanson JA. Osteosarcoma of the head and neck: meta-analysis of nonrandomized studies. The Laryngoscope 1997;107(1):56-61.
14. Gupta S, Chitra S, Singh D. Primary osteogenic sarcoma of skull bone-a rare clinical presentation. Internet J Oncol 2008;6(2)

15. Shinoda J, Kimura T, Funakoshi T, Iwata H, Tange $\mathrm{K}$, Kasai C et al. Primary osteosarcoma of the skull. Journal of neuro-oncology 1993;17(1):81-8. 